\title{
A randomized, controlled trial evaluating the efficacy and safety of BTH1677 in combination with bevacizumab, carboplatin, and paclitaxel in first-line treatment of advanced non-small cell lung cancer
}

Walburga Engel-Riedel', Jamie Lowe ${ }^{2}$, Paulette Mattson², J. Richard Trout ${ }^{3}$, Richard D. Huhn², Michele Gargano², Myra L. Patchen ${ }^{2,6 *}$, Richard Walsh ${ }^{2}$, My My Trinh $^{4}$, Mariève Dupuis ${ }^{4}$ and Folker Schneller ${ }^{5}$

\begin{abstract}
Background: BTH1677, a beta-glucan pathogen-associated molecular pattern molecule, drives an anti-cancer immune response in combination with oncology antibody therapies. This phase II study explored the efficacy, pharmacokinetics (PK), and safety of BTH1677 combined with bevacizumab/carboplatin/paclitaxel in patients with untreated advanced non-small cell lung cancer (NSCLC).

Methods: Patients were randomized to the BTH1677 arm ( $N=61$; intravenous [IV] BTH1677, $4 \mathrm{mg} / \mathrm{kg}$, weekly; IV bevacizumab, $15 \mathrm{mg} / \mathrm{kg}$, once each 3-week cycle [Q3W]; IV carboplatin, $6 \mathrm{mg} / \mathrm{mL} / \mathrm{min}$ Calvert formula areaunder-the-curve, Q3W; and IV paclitaxel, $200 \mathrm{mg} / \mathrm{m}^{2}$, Q3W) or Control arm ( $\mathrm{N}=31$; bevacizumab/carboplatin/ paclitaxel as above). Carboplatin/paclitaxel was discontinued after 4-6 cycles and patients who responded or remained stable received maintenance therapy with BTH1677/bevacizumab (BTH1677 arm) or bevacizumab (Control arm). Efficacy assessments, based on blinded central radiology review, included objective response rate (ORR; primary endpoint), disease control rate, duration of objective response, and progression-free survival. Overall survival and adverse events (AEs) were also assessed.
\end{abstract}

Results: ORR was higher in the BTH1677 vs Control arm but the difference between groups was not statistically significant (60.4\% vs 43.5\%; $P=$.2096). All other clinical endpoints also favored the BTH1677 arm but none statistically differed between arms. PK was consistent with previous studies. Although a higher incidence of Grade 3/4 AEs occurred in the BTH1677 vs Control arm (93.2\% vs 66.7\%), no unexpected AEs were observed. Serious AEs and discontinuations due to AEs were lower in the BTH1677 vs Control arm.

Conclusions: Improvements in tumor assessments and survival were observed with BTH1677/bevacizumab/carboplatin/ paclitaxel compared with control treatment in patients with advanced NSCLC.

(Continued on next page)

\footnotetext{
* Correspondence: mpatchen@immunoresearch.com

${ }^{2}$ Biothera Pharmaceuticals, Inc., 3388 Mike Collins Drive, Suite A, Eagan, MN

55121, USA

${ }^{6}$ PresentAddress: Immuno Research, Inc., 3388 Mike Collins Drive, Suite B,

Eagan, MN 55121, USA

Full list of author information is available at the end of the article
} 
(Continued from previous page)

Trial registration: ClinicalTrials.gov registration ID: NCT00874107. Registered 2 April 2009. First participant was enrolled on 29 September 2009.

Keywords: Immunotherapy, NSCLC, Bevacizumab, Beta-glucan

\section{Background}

Approximately $85 \%$ of all lung cancers are classified as non-small cell lung cancer (NSCLC) and the majority of patients present with locally advanced or metastatic disease [1]. Despite significant advances in NSCLC therapies, first-line treatment options for patients with advanced NSCLC still remain limited. Traditional platinum-based chemotherapy is still a mainstay therapy for most patients; however, this treatment approach generally provides only a short-lived benefit [2-4]. More recently, targeted therapies (eg, those targeting epidermal growth factor receptor [EGFR] gene mutations or anaplastic lymphoma kinase [ALK] translocations) have produced superior effects compared with chemotherapies for first-line management of advanced mutated NSCLC, but only small specific subtypes of NSCLC patients benefit from such treatments [2-4]. Several monoclonal antibody (MAb) therapies have also been approved for first-line treatment of advanced NSCLC, including bevacizumab (approved for nonsquamous only), which targets vascular endothelial growth factor (VEGF) [5]; necitumumab (approved for squamous only) [6], which targets EGFR; and most recently, pembrolizumab, which targets the programmed death-1 (PD-1) immune checkpoint receptor on cytotoxic $\mathrm{T}$ cells [7]. Additional MAbs approved for second-line therapy, but possibly moving to front-line therapy, include ramucirumab [8], which targets VEGF receptor 2 (VEGFR2), as well as the anti-PD-1 and anti-programmed death ligand-1 (PD-L1) MAbs, nivolumab [9] and atezolizumab [10], respectively.

VEGF can compromise immune cell function in the tumor microenvironment, which may then become favorable for tumor survival and growth [11, 12]. Bevacizumab blocks VEGF receptor signaling [13]. Anti-VEGF agents can also normalize the tortuous vasculature of tumors and facilitate infiltration of lymphocytes [11]. Bevacizumab is approved by the Food and Drug Administration for unresectable, locally advanced, recurrent or metastatic nonsquamous NSCLC in the first-line setting in combination with carboplatin/paclitaxel [14-16].

BTH1677 (Imprime PGG; $\beta(1,6)$-[poly-(1,3)-D-glucopyranosyl]-poly- $\beta-(1,3)-D$-glucopyranose; Biothera Pharmaceuticals, Inc., Eagan, MN) is a yeast-derived, watersoluble, 1,3-1,6 beta-glucan purified from the cell wall of a proprietary, non-recombinant, strain of Saccharomyces cerevisiae. It functions as a pathogen-associated molecular pattern (PAMP) molecule to support a coordinated innate and adaptive anti-cancer immune response in combination with oncology antibody therapies. When BTH1677 enters the blood, it is bound by endogenous plasma anti-beta-glucan antibodies (ABA) resulting in complement activation and opsonization with complement protein $\mathrm{iC} 3 \mathrm{~b}[17,18]$. The $\mathrm{BTH} 1677 / \mathrm{ABA} / \mathrm{iC} 3 \mathrm{~b}$ complex initially binds to innate immune effector cells through complement receptor 3 and Fc gamma receptor IIA (FcyIIA) [17, 18], activating innate immune cells and enabling direct killing of antibody-targeted tumor cells [17]. BTH1677 also enables remodeling of the tumor microenvironment, shifting the normally suppressive M2-state macrophages to a more M1 (pro-inflammatory) state [19-21], and promoting depletion and/or maturation of myeloid-derived suppressor cells in the tumor microenvironment [22, 23]. BTH1677 additionally activates antigen-presenting cells, driving co-stimulatory marker expression on macrophages and dendritic cells, as well as dendritic cell maturation, CD4 and CD8 T-cell expansion, and production of key anti-tumor cytokines (e.g., interferon gamma) [20, 24-27]. In murine syngeneic and xenogeneic tumor models, BTH1677 combined with various tumor-targeting MAbs [28-31], PD-1 and PD-L1 checkpoint-inhibiting MAbs [31-33], or VEGF/ VEGFR2-targeted MAbs [22, 23, 31, 34-37] has resulted in greater suppression of tumor growth and longer survival than with either agent alone. In particular, 3 of these later studies have demonstrated synergy of BTH1677 when used in combination with bevacizumab in multiple lung cancer models $[23,35,36]$. Thus, the combination of BTH1677 and bevacizumab is a rational immunotherapy for treatment of cancer.

BTH1677 has been well tolerated after single doses up to $6 \mathrm{mg} / \mathrm{kg}$ and after 7 daily doses up to $4 \mathrm{mg} / \mathrm{kg}$ in healthy subjects. Pharmacokinetic (PK) parameters were proportional with dose [38]. Additionally, BTH1677 in combination with cetuximab, with or without irinotecan, was well tolerated with promising signs of efficacy in a phase Ib/II study in patients with recurrent or progressive metastatic colorectal cancer [39]. We also recently reported that BTH1677 combined with cetuximab/carboplatin/paclitaxel significantly improved ORR compared with cetuximab/carboplatin/paclitaxel in first-line treatment of patients with advanced NSCLC [40].

Here, we report results of a randomized, open-label, multicenter, phase II study evaluating the antitumor efficacy, safety, and PK profile of BTH1677 when combined with 
bevacizumab and concomitant carboplatin and paclitaxel therapy in patients with previously untreated, advanced NSCLC.

\section{Methods \\ Study objectives}

The primary objective was to evaluate the ORR (complete response $[\mathrm{CR}]+$ partial response $[\mathrm{PR}]$ ) in each treatment arm. Secondary objectives included assessment of best response rate (CR, $\mathrm{PR}$, or stable disease $[\mathrm{SD}]$ rates), disease control rate (DCR; $C R+P R+S D)$, duration of objective tumor response (DOR), progression-free survival (PFS), and overall survival (OS) in each treatment arm. Safety within each arm and the PK profile of BTH1677 were also evaluated.

\section{Patient eligibility}

Patients, 18 to 75 years of age, provided written informed consent, and had histologically or cytologically confirmed non-squamous stage IIIB or IV NSCLC according to American Joint Committee on Cancer Staging v6 [41]; measurable disease as defined by Response Evaluation Criteria in Solid Tumors (RECIST) v1.0; Eastern Cooperative Oncology Group performance status (ECOG PS) 0 or 1; life expectancy of $>3$ months; adequate hematologic, renal, and hepatic function; and use of an effective contraceptive.

Exclusion criteria included prior systemic chemotherapy for lung cancer; previous radiation therapy to $>30 \%$ of active bone marrow or any radiation therapy within 3 weeks of Day 1; central nervous system metastases; uncontrolled hypertension; peripheral neuropathy $\geq$ Grade 2; fever $>38.5{ }^{\circ} \mathrm{C}$ within 3 days of Day 1 ; active yeast infection; human immunodeficiency virus/acquired immune deficiency syndrome, hepatitis B, or hepatitis C; connective tissue or autoimmune disease; previous organ or progenitor/stem cell transplant; history of myocardial infarction or any other unstable, uncontrolled heart disease; second malignancy within the previous 5 years (other than basal cell carcinoma, cervical intra-epithelial neoplasm, or curatively treated prostate cancer); known hypersensitivity to baker's yeast, murine proteins, or polyoxyethylated castor oil (Cremophor ${ }^{\circ} \mathrm{EL}$ ); previous exposure to bevacizumab or BTH1677; or investigational therapy within 30 days prior to Day 1 . Female patients were excluded if they were pregnant or breastfeeding.

\section{Study design and treatment plan}

This randomized, open-label, multicenter, phase II study was performed at sites in Germany and the United States and was conducted in full accordance with the Good Clinical Practice: Consolidated Guideline approved by the International Conference on Harmonisation and all other applicable national and local laws/regulations. All study materials were approved by the governing ethics committee or institutional review board at each site.

The study was designed to test the null hypothesis that the true ORR was $\leq 30 \%$ vs the alternative hypothesis that the true ORR in the BTH1677 arm would be at least $50 \%$. It was determined that 60 patients in the BTH1677 arm would provide $90 \%$ power for the hypotheses testing at an alpha level of 5\%. With 2:1 randomization, a sample size of 30 patients was determined for the Control arm.

Patients in the BTH1677 and Control arms were dosed in 3-week cycles. On Days 1, 8, and 15 of each cycle, patients in the BTH1677 arm were administered $4 \mathrm{mg} / \mathrm{kg}$ of BTH1677 intravenously (IV) over 2 to $4 \mathrm{~h}$ (depending on patient weight and total dose administered). On Day 1 of each cycle, patients in each arm were administered $15 \mathrm{mg} / \mathrm{kg}$ of bevacizumab IV over $90 \mathrm{~min}$. In the BTH1677 arm, bevacizumab was administered after BTH1677. On Day 2 of each cycle, IV carboplatin (dosed according to Calvert formula area under the curve [AUC] of $6 \mathrm{mg} / \mathrm{mL} \cdot \mathrm{min}$ over $30 \mathrm{~min})$ and IV paclitaxel $\left(200 \mathrm{mg} / \mathrm{m}^{2}\right.$ over $3 \mathrm{~h}$ ) were administered to all patients. No dosing occurred on Day 8 and Day 15 of the Control arm. Prior to each BTH1677 dosing, all patients were to receive low-dose corticosteroids and a histamine receptor-1 antagonist (e.g., $4 \mathrm{mg}$ of dexamethasone orally and $50 \mathrm{mg}$ of diphenhydramine IV). On Day 2 of each cycle, all patients were pre-medicated with the local clinic's regimen of corticosteroids and antihistamines prior to carboplatin and paclitaxel therapy.

Carboplatin and paclitaxel administration continued for at least 4 cycles, but could continue for up to 6 cycles at the investigator's discretion. Following completion of chemotherapy, patients who experienced a response (CR or $\mathrm{PR}$ ) or had remained stable (SD) were eligible to continue on maintenance therapy receiving BTH1677/bevacizumab (BTH1677 arm) or bevacizumab (Control arm).

\section{Study assessments}

Safety and tolerability were assessed by adverse events (AEs; National Cancer Institute Common Terminology Criteria for Adverse Events [CTCAE] v3.0), physical examinations, and laboratory tests.

Tumor response assessments were based on computed tomography (CT) scans performed every other cycle (i.e., at 6-week intervals). Blinded central radiology reviews were performed with tumor response assessed using a modified RECIST v1.0 criteria in which an initial response did not require a repeat assessment at a later time period for confirmation. All other RECIST v1.0 criteria were unmodified. 


\section{Pharmacokinetics}

Post-dosing blood samples were collected for PK assessments for BTH1677 on Day 1 of Cycles 1 and 3. Samples for BTH1677 trough level assessments were also obtained before weekly dosing on all other weeks of $\mathrm{Cy}$ cles 1 and 2, as well as prior to dosing of Cycle 3, Day 1. Serum BTH1677 levels were measured by a beta-glucan specific enzyme-linked immunosorbent assay (ELISA) developed at Biothera Pharmaceuticals, Inc., which had a lower limit of detection of $1.2 \mathrm{ng} / \mathrm{mL}$ and a lower limit of quantitation of $4.7 \mathrm{ng} / \mathrm{mL}$. Serum PK parameters were calculated using noncompartmental analysis (NCA) with NCA in WinNonlin ${ }^{\circ}$ v.2.

\section{Statistical analysis}

The analysis populations for the blinded central radiology tumor assessments, safety and survival analyses, and PK analyses are shown by treatment arm in Fig. 1. The analysis population for tumor assessments (primary efficacy population) was comprised of all randomized patients who received any amount of bevacizumab, carboplatin, or paclitaxel, with or without BTH1677, and who had an evaluable baseline CT scan assessment and at least 1 evaluable post-baseline CT scan assessment. The safety and survival populations were comprised of all randomized patients who received any amount of study drugs. The PK population was comprised of all patients who had at least $75 \%$ of the PK measurements available for any particular treatment cycle data set. The primary analysis data lock (which included all analyses except final OS) occurred on 21 March 2014. Data lock for final survival analysis occurred on 16 March 2016, which was approximately 3 years after the randomization date of the last patient enrolled into the study.

Efficacy and safety measures are displayed by treatment arm. Categorical data are presented by $n$ and \% for each category and continuous data are presented by mean and standard deviation. Kaplan-Meier estimates were utilized for time-to-event analyses and, where appropriate, 95\% confidence intervals $(\mathrm{CI})$ are provided. Comparisons between treatment arms were performed at a 0.05 level of significance. AEs are summarized by system organ class using the Medical Dictionary for Regulatory Activities v15.0.

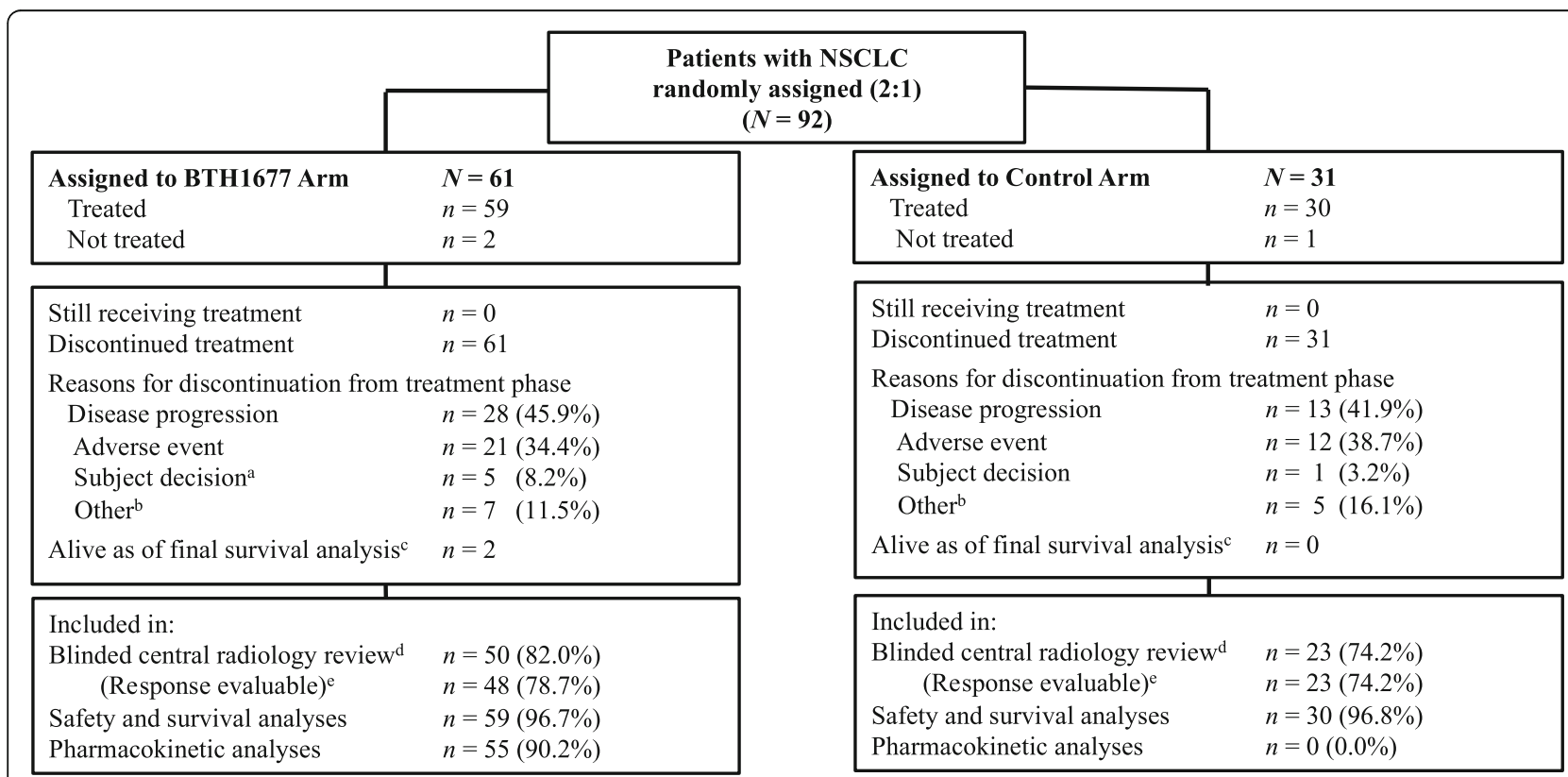

Fig. 1 Patient disposition. ${ }^{a}$ For 1 patient $(n=1)$, this occurred after primary data cut of 21 March 2014. ${ }^{\text {b }}$ For the BTH1677 arm, 'Other' included investigator decision ( $n=2)$, patient ineligibility $(n=2)$, radiotherapy following response $(n=1)$, tumor necrosis $(n=1)$, and sponsor ended study $(n=1)$; For the Control arm, 'Other' included planned surgery $(n=2)$, administrative decision $(n=1)$, investigator decision $(n=1)$, and sponsor ended study $(n=1)$. ${ }^{C}$ Final data lock for OS analysis (16 March 2016) was performed approximately 3 years after the randomization date of last patient enrolled into the study. ${ }^{d}$ Reasons for exclusion from efficacy analyses related to central radiology review in the BTH1677 arm were no evaluable baseline and/or post-baseline CT scan ( $n=10$; none of these patients had a best response of disease progression ie, clinical progression, reported by the investigator), and additionally 1 patient did not have histologically-confirmed NSCLC; in the Control arm, the primary reason for exclusion was no evaluable post-baseline CT scan ( $n=8 ; 2$ of these patients had a best response of disease progression ie, clinical progression, reported by the investigator). ${ }^{\text {e }}$ Per protocol, to be "response evaluable" patients with best response of stable disease had to exhibit this response for at least 42 days (6 weeks) post randomization - if last scan occurred prior to this they were not "response evaluable". Two patients in the BTH1677 arm were not evaluable for objective response, as their only on-study scan showed stable disease $<6$ weeks post randomization. Abbreviations: CT computed tomography, $N$ overall sample size, $n$ number of patients, NSCLC non-small cell lung cancer, OS overall survival 


\section{Results}

\section{Patient disposition}

Between 29 September 2009 and 08 March 2013, a total of 92 patients with NSCLC were randomly assigned 2:1 to the BTH1677 or the Control arm. As shown in Fig. 1, 59 patients in the BTH1677 arm and 30 patients in the Control arm were treated and included in the safety and survival analyses. The blinded central radiology review primary efficacy population included 50 patients (48 patients response evaluable) in the BTH1677 arm and 23 patients in the Control arm. The primary reason for patient exclusion from the primary efficacy population was that an evaluable baseline or post-baseline CT scan was not available or acceptable to the central radiology reviewers. The primary reason for treatment discontinuation in each arm was disease progression (BTH1677, 45.9\%; Control, 41.9\%).

Patient demographics and disease characteristics at baseline are shown in Table 1. The BTH1677 and Control arms were similar with respect to age, sex, race, as well as time from initial tumor diagnosis to diagnosis of stage IIIB/IV NSCLC and diagnosis of stage IIIB/IV NSCLC to randomization. The percentage of patients with ECOG PS status of 1 vs 0 was higher in the BTH1677 arm (47.5\%) than in the Control arm (33.3\%). The percentage of patients who received prior cancer treatments (radiotherapy, surgery, chemotherapy, hormonal, or other) was also higher in the BTH1677 arm compared with the Control arm.

Table 1 Patient demographics and disease characteristics at baseline (Safety population)

\begin{tabular}{|c|c|c|}
\hline & $\begin{array}{l}\text { BTH1677/ } \\
\text { Bevacizumab/Carboplatin/ } \\
\text { Paclitaxel } \\
(N=59)\end{array}$ & $\begin{array}{l}\text { Bevacizumab/ } \\
\text { Carboplatin/ } \\
\text { Paclitaxel } \\
(N=30)\end{array}$ \\
\hline \multicolumn{3}{|l|}{ Age (years) } \\
\hline Median (range) ${ }^{a}$ & $59(43,76)$ & $58(28,75)$ \\
\hline \multicolumn{3}{|l|}{ Sex, n (\%) } \\
\hline Male & $26(44.1)$ & $14(46.7)$ \\
\hline Female & $33(55.9)$ & $16(53.3)$ \\
\hline \multicolumn{3}{|l|}{ Race, n (\%) } \\
\hline White & 57 (96.6) & $30(100.0)$ \\
\hline Black & $1(1.7)$ & 0 \\
\hline Asian or Pacific Islander & $1(1.7)$ & 0 \\
\hline \multicolumn{3}{|l|}{ ECOG Performance Status, n (\%) } \\
\hline 0 & $31(52.5)$ & $20(66.7)$ \\
\hline 1 & $28(47.5)$ & $10(33.3)$ \\
\hline \multicolumn{3}{|l|}{ Disease stage at randomization } \\
\hline Stage IIIB & 0 & 0 \\
\hline Stage IV & $59(100.0)$ & $30(100.0)$ \\
\hline \multicolumn{3}{|c|}{ Time from initial tumor diagnosis to diagnosis of stage IIIB/IV NSCLC (days) ${ }^{b}$} \\
\hline Median (range) & $0(0,3158)$ & $0(0,0)$ \\
\hline \multicolumn{3}{|c|}{ Time from diagnosis of stage IIIB/IV NSCLC to randomization (days) ${ }^{c}$} \\
\hline Median (range) & $18(1,168)$ & $17.5(7,77)$ \\
\hline \multicolumn{3}{|c|}{ Time from initial tumor diagnosis to randomization (days) ${ }^{d}$} \\
\hline Median (range) & $20(1,3171)$ & $17.5(7,77)$ \\
\hline \multicolumn{3}{|l|}{ Prior cancer treatment, n (\%) } \\
\hline Radiotherapy & $2(3.4)$ & 0 \\
\hline Surgery & $8(13.6)$ & $2(6.7)$ \\
\hline Chemotherapy, hormonal, or other ${ }^{\mathrm{e}}$ & $2(3.4)$ & 0 \\
\hline
\end{tabular}

Abbreviations: ECOG Eastern Cooperative Oncology Group, $N$ overall sample size, $n$ number of patients, NSCLC non-small cell lung cancer

anclusion criteria restricted patients to 18 to 75 years of age but one 76 -year-old patient was inadvertently enrolled in the study

${ }^{\mathrm{b}}$ Time from initial tumor diagnosis to diagnosis of Stage IIIB/IV NSCLC = Stage IIIB/IV diagnosis date - initial tumor diagnosis date

'Time from diagnosis of Stage IIIB/IV NSCLC to randomization = Date of randomization - Stage IIIB/IV diagnosis date

${ }^{\mathrm{d}}$ Time from initial tumor diagnosis to randomization = Date of randomization -initial tumor diagnosis date

'Two patients in the BTH1677 arm received prior chemotherapy for lung cancer. Both patients were previous responders and received the prior chemotherapy greater than 6 months prior to enrollment 


\section{Efficacy}

\section{Tumor-associated assessments}

Tumor-associated assessments were based on the blinded central radiology review of the primary efficacy population. Although the between-group difference was not statistically significant, compared with the Control arm, patients in the BTH1677 arm had a higher ORR (60.4\% vs $43.5 \%$; $P=.2096)$ (Table 2 ). One patient in the BTH1677 arm had a CR while no patients in the Control arm had CR (Table 2 and Fig. 2). While on maintenance therapy, continued reduction in the sum of the longest diameters of target lesions of $>20 \mathrm{~mm}$ and $>10 \mathrm{~mm}$, respectively, occurred in $7 \%$ and $20 \%$ of the BTH 1677 arm patients, but in none of the Control arm patients (Table 3). One of these continued reductions included a BTH1677 arm patient who had a CR at treatment week 47 (Fig. 3); this patient remained in the study with a CR for an additional 19 weeks until the study was closed for primary analysis.

Of the patients with an objective response (BTH1677 $n=29$; Control $n=10$ ), the median DOR was 10.3 months in the BTH1677 arm (95\% CI: 5.6, not estimable) vs 5.6 months ( $95 \% \mathrm{CI}: 1.5$, not estimable) in the Control arm (HR 0.92 [95\% CI: 0.27, 4.20]; $P$ $=.9040$; Table 2 and Fig. 4a). DOR by patient is illustrated in Fig. 4b. Of the patients with progressive

Table 2 Tumor-associated assessments based on a blinded central radiology review of the primary efficacy population

\begin{tabular}{|c|c|c|c|c|c|}
\hline & \multicolumn{2}{|c|}{$\begin{array}{l}\text { BTH1677/Bevacizumab/ } \\
\text { Carboplatin/Paclitaxel } \\
\text { (N=48) }\end{array}$} & \multicolumn{2}{|c|}{$\begin{array}{l}\text { Bevacizumab/ } \\
\text { Carboplatin/Paclitaxel } \\
(N=23)\end{array}$} & \multirow[b]{2}{*}{$P$ value $^{\mathrm{f}}$} \\
\hline & $\mathrm{n}(\%)$ & $95 \% \mathrm{Cl}$ & $\mathrm{n}(\%)$ & $95 \% \mathrm{Cl}$ & \\
\hline Objective Response Rate $e^{a, b}$ & $29(60.4)$ & $(45.3,74.2)$ & $10(43.5)$ & $(23.2,65.5)$ & 0.2096 \\
\hline Disease Control Rate ${ }^{b, c}$ & $45(93.8)$ & $(82.8,98.7)$ & $21(91.3)$ & $(72.0,98.9)$ & 0.6563 \\
\hline \multicolumn{6}{|l|}{ Best Observed Response ${ }^{\mathrm{b}}$} \\
\hline Complete response & $1(2.1)$ & $(0.1,11.1)$ & 0 & NA & \\
\hline Partial response & $28(58.3)$ & $(43.2,72.4)$ & $10(43.5)$ & $(23.2,65.5)$ & 0.3113 \\
\hline Stable disease & $16(33.3)$ & $(20.4,48.4)$ & $11(47.8)$ & $(26.8,69.4)$ & 0.2992 \\
\hline Progressive disease & $3(6.3)$ & $(1.3,17.2)$ & $2(8.7)$ & $(1.1,28.0)$ & 0.6563 \\
\hline Duration of Objective Tumor Response $^{d}$ & & & & & $\mathrm{HR}(95 \% \mathrm{Cl})^{9}$ \\
\hline Patients with objective response $(C R+P R)$ & 29 & & 10 & & \\
\hline Patients (\% responding patients) with known duration (uncensored) & $9(31.0)$ & & $3(30.0)$ & & \\
\hline Patients (\% responding patients) with unknown duration (censored) & $20(69.0)$ & & $7(70.0)$ & & \\
\hline \multicolumn{6}{|l|}{ Duration of objective response (months) } \\
\hline Median $(95 \% \mathrm{Cl})$ & \multirow{2}{*}{\multicolumn{2}{|c|}{$10.3(5.6, \mathrm{NE})$}} & \multicolumn{2}{|l|}{$5.6(1.5, \mathrm{NE})$} & $0.92(0.27,4.20)$ \\
\hline Log-rank $P$ value & & & & & 0.9040 \\
\hline Progression-Free Survival ${ }^{e}$ & & & & & $\operatorname{HR}(95 \% \mathrm{Cl})^{9}$ \\
\hline Patients with PD or died, $\mathrm{n}(\%)$ & $17(34.0)$ & & $6(26.1)$ & & \\
\hline Patients censored, n (\%) & $33(66.0)$ & & $17(73.9)$ & & \\
\hline \multicolumn{6}{|l|}{ Progression-free survival (months) } \\
\hline Median $(95 \% \mathrm{Cl})$ & $11.6(7.0, \mathrm{NE})$ & & $9.6(7.1, \mathrm{NE})$ & & $1.31(0.54,3.65)$ \\
\hline Log-rank $P$ value & & & & & 0.5639 \\
\hline
\end{tabular}

Abbreviations: $C l$ confidence interval, $C R$ complete response, $N A$ not applicable, $P D$ progressive disease, $P R$ partial response, $H R$ hazard ratio, $n$ number of patients, $N$ overall sample size, $N E$ not estimable

${ }^{a}$ Objective response rate was defined as the percent of central radiology review response-evaluable patients experiencing a best overall tumor response of either CR or PR at any time on study according to modified RECIST v1.0 criteria

${ }^{b}$ Tumor response data reported as the number ( $n$ ) and percent (\%) of response-evaluable patients and the $95 \%$ exact binomial confidence interval ${ }^{\mathrm{C}}$ Disease control rate was defined as the percent of blinded central radiology review response-evaluable patients experiencing a best overall tumor response of CR, PR, or stable disease (SD) per modified RECIST v1.0 criteria

${ }^{d}$ Duration of objective response (months) was based on Kaplan-Meier estimates and was measured from the time at which criteria were met for CR or PR (whichever status was recorded first) until the first date on which recurrence or progressive disease (PD) was objectively documented per modified RECIST v1.0. Patients who did not progress as of the data cutoff date were censored at their last tumor assessment

e Progression-free survival (PFS) (months) was based on Kaplan-Meier estimates from the total blinded central radiological review population (BTH1677/Bevacizumab/Carboplatin/Paclitaxel, $n=50$ and Bevacizumab/Carboplatin/Paclitaxel, $n=23$ ) and was defined as the time from randomization to the first date of documented PD or death. PD was identified by radiologic PD according to modified RECIST v1.0. If a patient received any further anticancer therapy without prior documentation of PD, the patient was censored at the date of last imaging assessment before the treatment. Patients who were lost to follow-up or who were alive without PD as of the data cut-off date were censored at the last imaging assessment date or at the analysis data cut-off date, whichever came first f $P$ value was obtained using Fisher's Exact Test

${ }^{9}$ Hazard ratio $(95 \%$ exact binomial $\mathrm{Cl}$ ) was based on Cox proportional hazards model with treatment as factor 


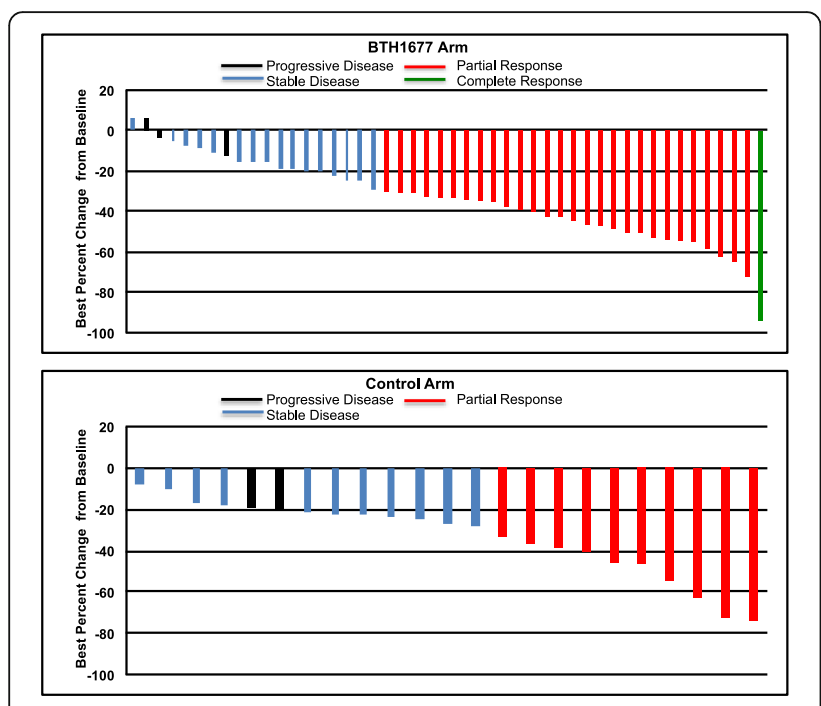

Fig. 2 Maximum reduction from baseline in sum of longest diameters (SLD) for target lesions. Blinded central radiology review data from individual patients in the primary efficacy population

disease or death (BTH1677 $n=17$; Control $n=6$ ), the PFS was 11.6 months in the BTH1677 arm and 9.6 months in the Control arm (HR 1.31 [95\% CI: 0.54, 3.65]; $P=.5639$; Table 2).

\section{Overall survival}

The OS Kaplan-Meier curves for the BTH1677 and Control arms are shown in Fig. 5. The median OS of patients in the BTH1677 arm was 16.1 months (95\% CI: 11.4, 20.8) compared with 11.6 months (95\% CI: $7.7,22.3)$ in the Control arm. However, the difference in median OS was not statistically significant between arms (HR 0.75 [95\% CI: 0.45, 1.28]; $P=.2696$ ).
Table 3 Change in target lesion sum of longest diameters from post-chemotherapy baseline to post-chemotherapy nadir

\begin{tabular}{lll}
\hline $\begin{array}{l}\text { Length of SLD } \\
\text { Reduction (mm) }\end{array}$ & $\begin{array}{l}\text { BTH1677/ } \\
\text { Bevacizumab/Carboplatin/ } \\
\text { Paclitaxel } \\
(N=30)\end{array}$ & $\begin{array}{l}\text { Bevacizumab/Carboplatin/ } \\
\text { Paclitaxel } \\
(N=13)\end{array}$ \\
\hline$>20$ & $2(7 \%)$ & 0 \\
$>10$ & $6(20 \%)$ & 0 \\
$>5$ & $10(33 \%)$ & $2(15 \%)$
\end{tabular}

Abbreviations: $N$ overall sample size, $S L D$ sum of longest diameters

${ }^{a}$ Number of patients continuing in study on maintenance therapy with at least 2 post-chemotherapy tumor assessments based on blinded central radiology review of the primary efficacy population

\section{Safety}

All patients receiving any treatment (BTH1677 $n=59$; Control $n=30$ ) were included in the safety population, and the majority of these patients $(\geq 98 \%)$ experienced at least $1 \mathrm{AE}$. Grade 3 or Grade 4 AEs occurred at a higher incidence among patients in the BTH1677 arm compared with patients in the Control arm (93.2\% vs $66.7 \%$, respectively). However, the incidence of serious AEs (40.7\% vs $43.3 \%)$ and AEs leading to discontinuation ( $35.6 \%$ vs $40 \%$ ) was slightly lower in the BTH1677 arm than the Control arm, respectively. In the BTH1677 arm, $22.0 \%$ and $28.8 \%$ of the AEs were considered probably and possibly related to BTH1677, respectively. These data are summarized in Table 4 .

AEs of any grade that occurred in $\geq 10 \%$ of patients in the BTH1677 and Control arms are presented in Table 5 . Gastrointestinal, general, hematological, and skin disorders were commonly reported AEs among both arms. Of the AEs reported in these categories, neutropenia, leukopenia, nausea, constipation, vomiting, abdominal pain upper, stomatitis, pyrexia, and chills occurred at an incidence at least 5\% higher in the BTH1677 arm than in the Control arm; of these AEs, stomatitis and chills occurred exclusively in the BTH1677 arm (10.2\% vs $0 \%$ and $18.6 \%$ vs $0 \%$, respectively).

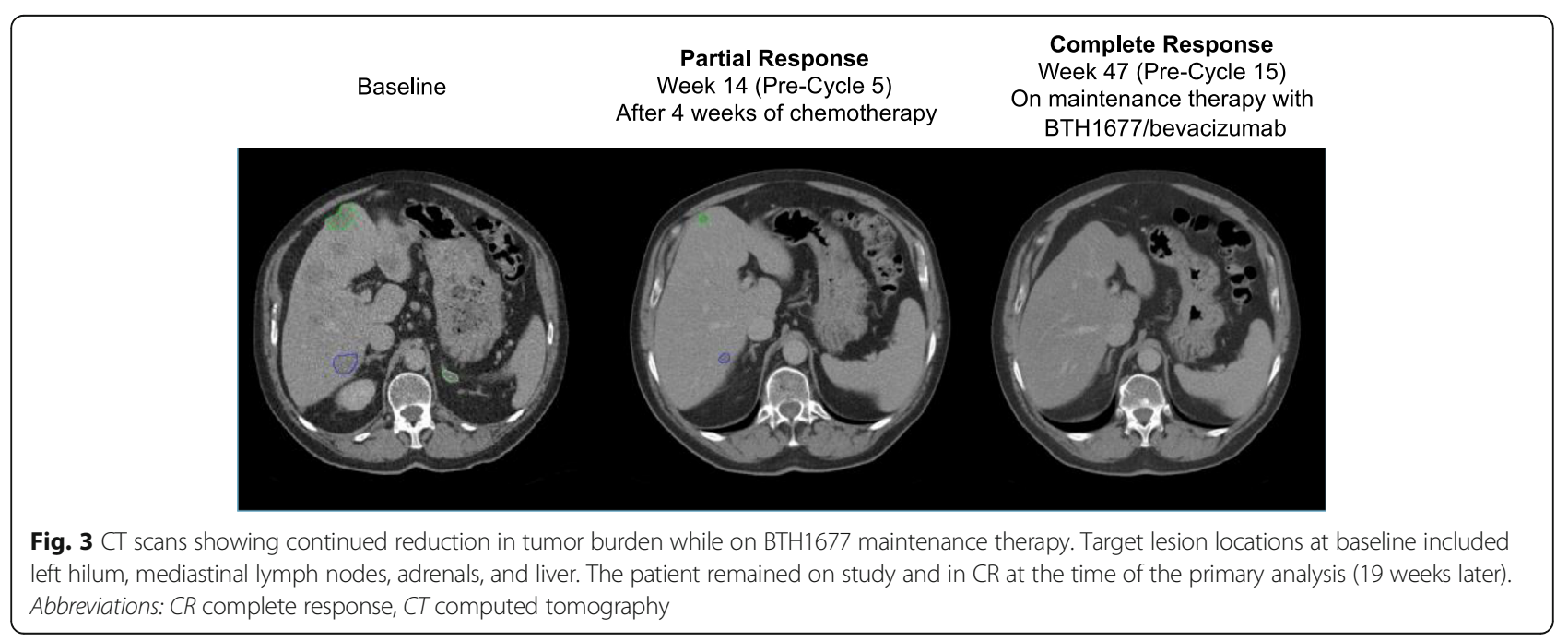




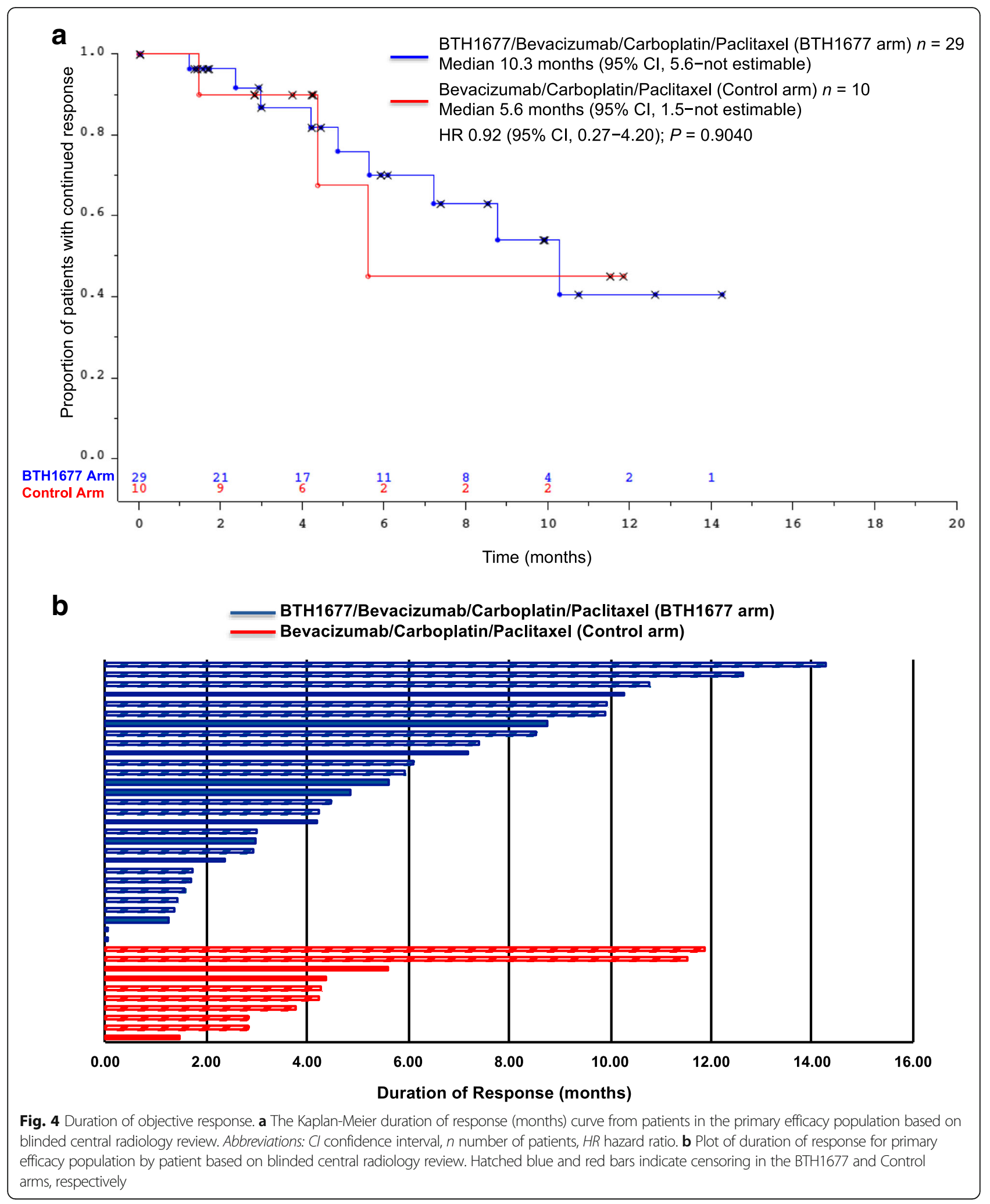

In contrast, diarrhea and chest pain occurred at an incidence at least 5\% higher in the Control arm than in the BTH1677 arm.
For AEs of any grade that occurred in $\geq 10 \%$ of patients, those that were Grade 3 or Grade 4 are also presented in Table 5. For purposes of comparison here, 


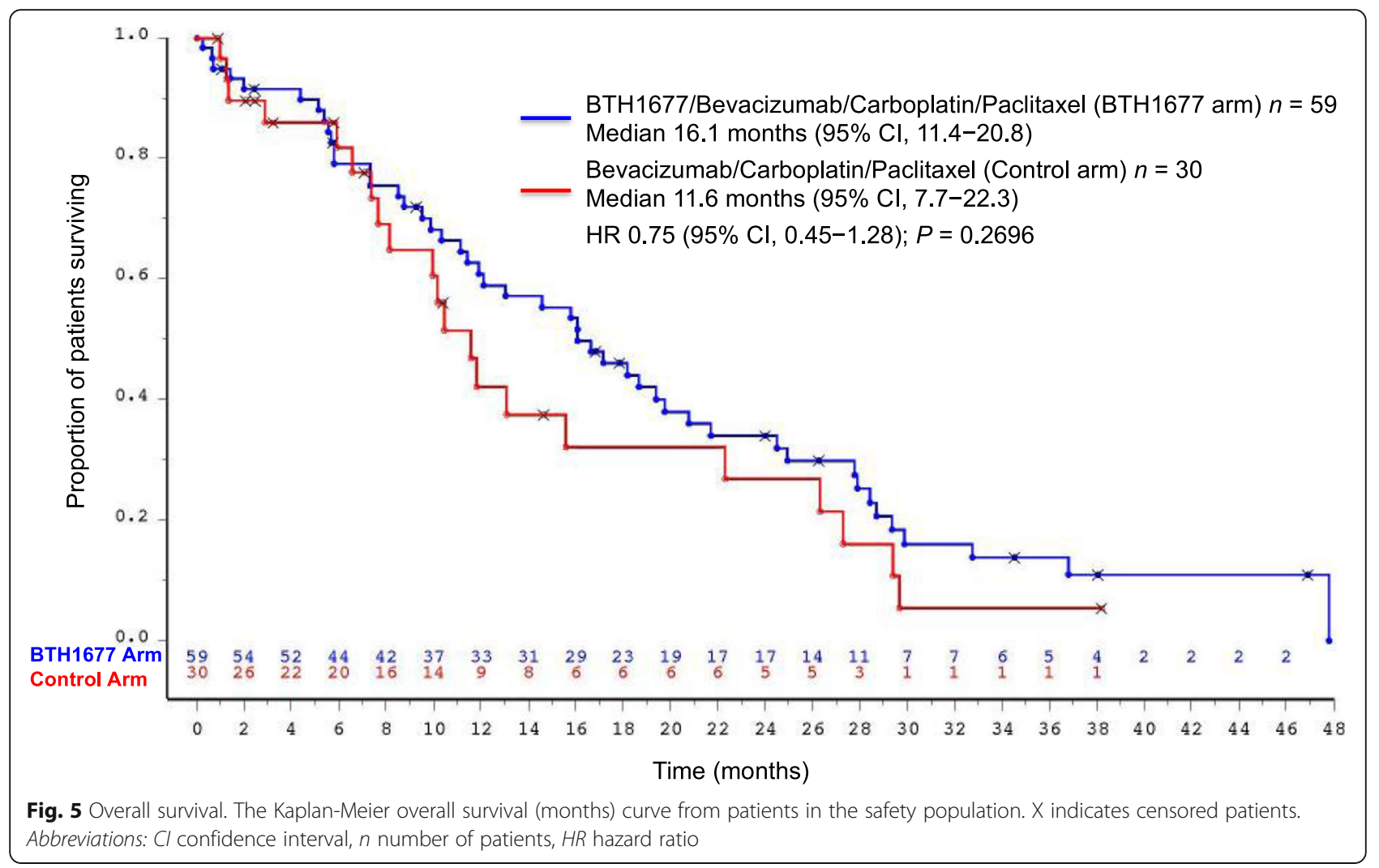

Grade 3 or Grade 4 AEs that occurred in $\geq 5 \%$ of patients in either treatment arm included neutropenia $(39.0 \%$ BTH1677 vs $26.7 \%$ Control), thrombocytopenia (18.6\% BTH1677 vs 16.7\% Control), leukopenia (5.1\% BTH1677 vs $3.3 \%$ Control), nausea (8.5\% BTH1677 vs $0 \%$ Control), hemoglobin decreased (1.7\% BTH1677 vs $6.7 \%$ Control), polyneuropathy (5.1\% BTH1677 vs 0\% Control), dyspnea (5.1\% BTH1677 vs 0\% Control), and hypertension (5.1\% BTH1677 vs 3.3\% Control).

Eight deaths (7 in the BTH1677 arm; 1 in the Control arm) were reported in the treatment phase of within

Table 4 Overview of safety outcomes (Safety population)

\begin{tabular}{lll}
\hline Adverse events (AEs), $\mathrm{n}(\%)$ & $\begin{array}{l}\text { BTH1677/ } \\
\text { Bevacizumab/ } \\
\text { Carboplatin/Paclitaxel } \\
(\mathrm{N}=59)\end{array}$ & $\begin{array}{l}\text { Bevacizumab/ } \\
\text { Carboplatin/ } \\
\text { Paclitaxel } \\
(\mathrm{N}=30)\end{array}$ \\
\hline Any AE & $58(98.3)$ & $30(100.0)$ \\
NCI/CTCAE Grade 3 or 4 AEs & $55(93.2)$ & $20(66.7)$ \\
Serious AEs & $24(40.7)$ & $13(43.3)$ \\
BTH1677-related AEs & $13(22.0)$ & NA \\
Probably related & $17(28.8)$ & NA \\
Possibly related & $21(35.6)$ & $12(40.0)$ \\
AEs leading to discontinuation
\end{tabular}

Abbreviations: $A E$ adverse events, $N$ overall sample size, $n$ number of patients, NA not applicable, NCI/CTCAE National Cancer Institute Common Terminology Criteria for Adverse Events
30 days of the last dose of study medication. Six of the 7 deaths in the BTH1677 arm were due to disease progression or complications of disease progression (e.g., pneumonia due to lung cancer, pneumothorax); the other death was due to intracranial hemorrhage that occurred subsequent to administration of anticoagulant for a blood clot in the lung. The 1 death in the Control arm was due to complications of disease progression (pneumonia due to lung cancer).

\section{BTH1677 pharmacokinetics}

BTH1677 serum concentrations in both cycles were above the limit of quantitation $(4.7 \mathrm{ng} / \mathrm{mL})$ for all but 1 patient. Individual $t_{\max }$ values generally coincided with the end of infusion or shortly thereafter. Mean serum trough levels of BTH1677 appeared to plateau as of Day 15 of Cycle 1, suggesting that steady state was achieved as of Day 15. Table 6 summarizes the PK parameters of BTH1677 from Cycle 1/Day $1(n=53)$ and Cycle 3/Day $1(n=42)$. Geometric mean $C_{\max }$ of serum BTH1677 was similar in Cycle $1(49.77 \mu \mathrm{g} / \mathrm{mL})$ and Cycle $3(60.50 \mu \mathrm{g} / \mathrm{mL})$. AUC $\mathrm{AU}_{24}$ of BTH1677 was also similar in Cycle $1(399.8 \mu \mathrm{g} \cdot \mathrm{hr} . / \mathrm{mL})$ and Cycle 3 (464.4 $\mu \mathrm{g} \cdot \mathrm{hr} . / \mathrm{mL})$, with little to no accumulation of BTH1677 being observed. No notable difference in other PK parameters $\left(\mathrm{CL}, \mathrm{t}_{\max }\right.$, and $\left.\mathrm{V}_{\mathrm{ss}}\right)$ between Cycle 1 and Cycle 3 were observed. A longer elimination half- 
Table 5 Any grade AEs ( $\geq 10 \%)$ and corresponding Grade 3 or 4 AEs (Safety population)

\begin{tabular}{|c|c|c|c|c|}
\hline \multirow[b]{2}{*}{ Adverse events (AEs), n (\%) } & \multicolumn{2}{|c|}{$\begin{array}{l}\text { BTH1677/ } \\
\text { Bevacizumab/ } \\
\text { Carboplatin/Paclitaxel } \\
(N=59)\end{array}$} & \multicolumn{2}{|c|}{$\begin{array}{l}\text { Bevacizumab/ } \\
\text { Carboplatin/Paclitaxel } \\
(\mathrm{N}=30)\end{array}$} \\
\hline & All AEs & Grade 3 or Grade 4 AEs & All AEs & Grade 3 or Grade 4 AEs \\
\hline Patients with at least $1 \mathrm{AE}$ & $58(98.3)$ & $55(93.2)$ & $30(100.0)$ & $20(66.7)$ \\
\hline \multicolumn{5}{|c|}{ Blood and lymphatic system disorders } \\
\hline Neutropenia & $26(44.1)$ & $23(39.0)$ & $10(33.3)$ & $8(26.7)$ \\
\hline Thrombocytopenia & $20(33.9)$ & $11(18.6)$ & $10(33.3)$ & $5(16.7)$ \\
\hline Anemia & $14(23.7)$ & $2(3.4)$ & $8(26.7)$ & $1(3.3)$ \\
\hline Leukopenia & $9(15.3)$ & $3(5.1)$ & $2(6.7)$ & $1(3.3)$ \\
\hline \multicolumn{5}{|l|}{ Gastrointestinal disorders } \\
\hline Nausea & $40(67.8)$ & $5(8.5)$ & $16(53.3)$ & 0 \\
\hline Constipation & $25(42.4)$ & 0 & $9(30.0)$ & 0 \\
\hline Vomiting & $19(32.2)$ & $2(3.4)$ & $7(23.3)$ & 0 \\
\hline Diarrhea & $12(20.3)$ & $2(3.4)$ & $8(26.7)$ & $1(3.3)$ \\
\hline Abdominal pain upper & $6(10.2)$ & $1(1.7)$ & $1(3.3)$ & 0 \\
\hline Stomatitis & $6(10.2)$ & $1(1.7)$ & 0 & 0 \\
\hline \multicolumn{5}{|c|}{ General disorders and administration-site conditions } \\
\hline Fatigue & $33(55.9)$ & $1(1.7)$ & $18(60.0)$ & $1(3.3)$ \\
\hline Pyrexia & $12(20.3)$ & $2(3.4)$ & $3(10.0)$ & 0 \\
\hline Chills & $11(18.6)$ & $1(1.7)$ & 0 & 0 \\
\hline Mucosal inflammation & $6(10.2)$ & 0 & $3(10.0)$ & 0 \\
\hline Chest pain & $3(5.1)$ & 0 & $5(16.7)$ & 0 \\
\hline \multicolumn{5}{|l|}{ Infections and infestations } \\
\hline Nasopharyngitis & $6(10.2)$ & 0 & $3(10.0)$ & 0 \\
\hline Urinary tract infection & $2(3.4)$ & $1(1.7)$ & $3(10.0)$ & 0 \\
\hline \multicolumn{5}{|c|}{ Injury, poisoning, and procedural complications } \\
\hline Infusion-related reaction & $7(11.9)$ & $1(1.7)$ & $2(6.7)$ & $1(3.3)$ \\
\hline \multicolumn{5}{|l|}{ Investigations } \\
\hline Hemoglobin decreased & $4(6.8)$ & $1(1.7)$ & $3(10.0)$ & $2(6.7)$ \\
\hline Platelet count decreased & $3(5.1)$ & $2(3.4)$ & $3(10.0)$ & $1(3.3)$ \\
\hline \multicolumn{5}{|c|}{ Metabolism and nutritional disorders } \\
\hline Decreased appetite & $17(28.8)$ & $1(1.7)$ & $11(36.7)$ & 0 \\
\hline Hypokalemia & $6(10.2)$ & $1(1.7)$ & 0 & 0 \\
\hline \multicolumn{5}{|c|}{ Musculoskeletal and connective tissue disorders } \\
\hline Arthralgia & $19(32.2)$ & $1(1.7)$ & $6(20.0)$ & 0 \\
\hline Pain in extremity & $15(25.4)$ & 0 & $3(10.0)$ & 0 \\
\hline Back pain & $11(18.6)$ & $1(1.7)$ & $4(13.3)$ & 0 \\
\hline Myalgia & $12(20.3)$ & $1(1.7)$ & $2(6.7)$ & 0 \\
\hline \multicolumn{5}{|l|}{ Nervous system disorders } \\
\hline Polyneuropathy & $16(27.1)$ & $3(5.1)$ & $6(20.0)$ & 0 \\
\hline Headache & $9(15.3)$ & $1(1.7)$ & $4(13.3)$ & 0 \\
\hline Neuropathy peripheral & $6(10.2)$ & 0 & $5(16.7)$ & 0 \\
\hline Dizziness & $7(11.9)$ & 0 & $3(10.0)$ & 0 \\
\hline Paresthesia & $7(11.9)$ & 0 & $2(6.7)$ & 0 \\
\hline Dysgeusia & $6(10.2)$ & 0 & $2(6.7)$ & 0 \\
\hline
\end{tabular}


Table 5 Any grade AEs ( $\geq 10 \%)$ and corresponding Grade 3 or 4 AEs (Safety population) (Continued)

\begin{tabular}{|c|c|c|c|c|}
\hline \multirow[b]{2}{*}{ Adverse events (AEs), n (\%) } & \multicolumn{2}{|c|}{$\begin{array}{l}\text { BTH1677/ } \\
\text { Bevacizumab/ } \\
\text { Carboplatin/Paclitaxel } \\
(N=59)\end{array}$} & \multicolumn{2}{|c|}{$\begin{array}{l}\text { Bevacizumab/ } \\
\text { Carboplatin/Paclitaxel } \\
(N=30)\end{array}$} \\
\hline & All AEs & Grade 3 or Grade 4 AEs & All AEs & Grade 3 or Grade 4 AEs \\
\hline \multicolumn{5}{|l|}{ Psychiatric disorders } \\
\hline Insomnia & $9(15.3)$ & 0 & $2(6.7)$ & 0 \\
\hline Sleep disorder & $5(8.5)$ & 0 & $4(13.3)$ & 0 \\
\hline \multicolumn{5}{|c|}{ Respiratory, thoracic and mediastinal disorders } \\
\hline Dyspnea & $18(30.5)$ & $3(5.1)$ & $8(26.7)$ & 0 \\
\hline Cough & $18(30.5)$ & $2(3.4)$ & $7(23.3)$ & 0 \\
\hline Epistaxis & $14(23.7)$ & 0 & $10(33.3)$ & 0 \\
\hline Oropharyngeal pain & $8(13.6)$ & 0 & $2(6.7)$ & 0 \\
\hline \multicolumn{5}{|c|}{ Skin and subcutaneous tissue disorders } \\
\hline Alopecia & $28(47.5)$ & $2(3.4)$ & $14(46.7)$ & 0 \\
\hline \multicolumn{5}{|l|}{ Vascular disorders } \\
\hline Hypertension & $14(23.7)$ & $3(5.1)$ & $7(23.3)$ & $1(3.3)$ \\
\hline
\end{tabular}

Abbreviations: $A E$ adverse events, $N$ overall sample size, $n$ number of patients

life $\left(\mathrm{t}_{1 / 2}\right)$ was observed in Cycle $1(17.56 \mathrm{~h})$ than Cycle 3 (7.17 h); however, these results should be interpreted with caution given the difference in sampling periods between Cycle 1 (up to $168 \mathrm{~h}$ post dosing) and Cycle 3 (only up to $24 \mathrm{~h}$ post dosing).

\section{Discussion}

It has only been in recent years that harnessing the immune system in the fight against cancer has become well appreciated, especially with respect to therapy of NSCLC [42-46]. BTH1677 is a novel PAMP molecule capable of inducing coordinated innate and adaptive immune responses. BTH1677 is being developed for the treatment of cancer in combination with tumor-targeted, anti-angiogenic, and checkpoint inhibitor antibodies. Here we report the effects of BTH1677 combined with the anti-angiogenic MAb, bevacizumab, and platinumbased chemotherapy in first-line treatment of advanced non-squamous NSCLC patients.

Previously the ECOG and AVAiL trials [14-16] evaluated clinical outcomes when bevacizumab was added to a platinum-based chemotherapy backbone in patients with advanced non-squamous NSCLC in a first-line setting. In particular, the ECOG study evaluated the same chemotherapy backbone of carboplatin and paclitaxel as our current study [14]. In this randomized, open-label, phase II study, ORR, DOR, PFS, and OS were higher in patients receiving BTH1677 in combination with bevacizumab, carboplatin, and paclitaxel compared with patients receiving bevacizumab, carboplatin, and paclitaxel alone. As statistical significance was not achieved in any of the assessments, all results should be interpreted carefully. As a phase II study, its main goal was to better
Table 6 Summary of BTH1677 pharmacokinetics parameters

\begin{tabular}{|c|c|c|}
\hline \multirow[t]{3}{*}{ Parameters } & \multicolumn{2}{|c|}{ Geometric Mean (CV\%) } \\
\hline & \multicolumn{2}{|c|}{$\begin{array}{l}\text { BTH1677/Bevacizumab/ } \\
\text { Carboplatin/Paclitaxel }\end{array}$} \\
\hline & Cycle 1/Day 1 & Cycle 3/Day 1 \\
\hline $\bar{N}$ & $53^{b}$ & 42 \\
\hline$A \cup C_{0-\text { last }}(\mu \mathrm{g} \cdot \mathrm{hr} . / \mathrm{mL})$ & $614.6(52.0)$ & $423.5(48.1)$ \\
\hline$A \cup C_{0-24}(\mu \mathrm{g} \cdot h \mathrm{hr} / \mathrm{mL})$ & $399.8(37.3)$ & $464.4(38.9)^{d}$ \\
\hline$A \cup C_{0-\infty}(\mu \mathrm{g} \cdot h r . / m L)$ & $635.9(49.5)^{c}$ & $518.6(42.2)^{e}$ \\
\hline$C_{\max }(\mu \mathrm{g} / \mathrm{mL})$ & $49.77(36.1)$ & $60.50(49.2)$ \\
\hline$C L(L / h)$ & $0.441(47.3)^{c}$ & $0.548(41.6)^{\mathrm{e}}$ \\
\hline$t_{1 / 2}(h r)$ & $17.56(36.9)^{c}$ & $7.17(35.3)^{\mathrm{e}}$ \\
\hline$t_{\max }(h r)^{a}$ & $2.48(1.52,5.90)$ & $2.37(1.92,6.88)$ \\
\hline$V_{s s}(L)$ & $5.37(42.4)^{c}$ & $4.13(51.5)^{\mathrm{e}}$ \\
\hline$R(A \cup C)$ & NA & $1.10(27.3)^{d}$ \\
\hline
\end{tabular}

Abbreviations: $A \cup C_{(0-\text {-ast })}$ area under the serum concentration-time curve from time 0 to the time of the last measurable concentration, $A \cup C_{0-24}$ area under the serum concentration-time curve from time 0 to $24 \mathrm{~h}, A U C_{0-\infty}$ area under the serum concentration-time curve from time 0 to infinity, $C_{\max }$ maximum serum concentration, $C L$ systemic clearance, $C V$ coefficient of variation, $h r$. hour, $L$ liter, $m L$ milliliter, $N$ overall sample size, $N A$ not applicable, $R$ (AUC) accumulation ratio calculated as $\mathrm{AUC}_{0-24}$ (Cycle 3)/AUC $0-24$ (Cycle 1), $t_{1 / 2}$ elimination half-life, $t_{\max }$ time of maximum concentration, $\mu \mathrm{g}$ microgram, $V_{s s}$ volume of distribution at steady-state

${ }^{a}$ Median (range)

${ }^{\mathrm{b}}$ Although 2 other patients met the basic criteria for inclusion in the PK population (ie, having at least $75 \%$ of the PK measurements available for any particular treatment cycle data set), 2 patients were subsequently excluded from analysis. One patient received a second unplanned BTH1677 infusion on Day 2 of Cycle 1 and a second patient had a longer infusion time $(5.58 \mathrm{~h})$ relative to the other patients for Cycle 1/Day 1. Both of these differences were deemed to likely result in PK differences relative to other patients in Cycle 1 and were excluded

${ }^{\mathrm{c}} \mathrm{N}=50$

$\mathrm{d}_{N}=37$

${ }^{\mathrm{e}} \mathrm{N}=31$ 
define the point estimates and variability of the efficacy parameters to be used for statistical design in a later registrational trial. The consistent positive trend across multiple clinical endpoints suggests a benefit with the addition of BTH1677 to bevacizumab, carboplatin, and paclitaxel and is consistent with synergistic effects seen with preclinical in vivo studies with BTH1677 added to bevacizumab therapy in murine lung cancer models [23, $35,36]$. It should also be noted that the Control arm in this trial performed similarly to, or better than, the bevacizumab/carboplatin/paclitaxel arm in the ECOG 4599 study (ECOG ORR $35 \%$ vs our 43.5\%; ECOG PFS 6.2 months vs our 9.6 months; ECOG OS 12.3 months vs our 11.6 months), giving credibility to the further improvements of $60.4 \%, 11.6$ months, and 16.1 months observed for these respective endpoints with the addition of BTH1677.

The most frequently reported $\mathrm{AE}$ system organ classes were blood and lymphatic system disorders, gastrointestinal disorders, and general disorders/administration site conditions, which are consistent with $\mathrm{AE}$ classes typically associated with the underlying disease and/or the backbone therapy. Although an overall higher incidence of Grade 3 or Grade 4 AEs was reported in the BTH1677 arm than the Control arm, fewer patients in the BTH1677 arm than in the Control arm discontinued therapy due to AEs. It has subsequently been observed in ongoing cancer trials that infusion reactions may be associated with BTH1677 administration in some patients and may consist of various constellations of transient fever/chills, headache, dyspnea/cough, nausea, vomiting, abdominal pain, back pain, and myalgia/arthralgia; such events were observed at Grade 3 levels and contributed to the overall higher incidence of Grade 3 or Grade 4 AEs in the BTH1677 arm of this trial. Fatal AEs reported in the BTH1677 arm were generally associated with progression of disease. Overall, these safety findings further support a safety profile for BTH1677, which is consistent with our previous reports with BTH1677 alone [38] or in combination with MAb and chemotherapy in patients with metastatic colorectal cancer [39] and advanced NSCLC [40].

Currently, the most notable immunotherapies recognized as impacting clinical outcomes in oncology are the checkpoint inhibitors (CPIs), among which pembrolizumab [7], nivolumab [9], and atezolizumab [10] (PD-1/PD-L1 CPIs) have been approved for various stages of NSCLC. In earlyphase studies, these agents are also being evaluated in combination with anti-angiogenic agents, including bevacizumab (with and without concomitant chemotherapy), with results pending [47]. These studies further support the concept of our study design to combine immunotherapy and an anti-angiogenic agent in hope of identifying an improved therapeutic approach for NSCLC patients.

\section{Conclusion}

In conclusion, BTH1677 in combination with bevacizumab/carboplatin/paclitaxel as a first-line treatment of advanced NSCLC led to improvements in ORR, DOR, PFS, and OS compared with the Control arm. No major safety concerns were noted with the BTH1677 combination therapy. Ongoing studies are continuing to explore this novel PAMP immune modulator as an adjunct to antibody-based therapy, including checkpoint inhibitor therapies, for patients with NSCLC (NCT03003468) as well as other cancers (NCT02086175; NCT02981303).

\section{Abbreviations}

ABA: Anti-beta-glucan antibodies; AE: Adverse events; ALK: Anaplastic lymphoma kinase; AUC: Area under the curve; $\mathrm{AUC}_{0-24}$ : Area under the serum concentration-time curve from time 0 to $24 \mathrm{~h}$; Cl: Confidence intervals; $\mathrm{CL}$ : Systemic clearance; $\mathrm{C}_{\text {max: }}$ Maximum serum concentration; CPI: Checkpoint inhibitors; CR: Complete response; CT: Computed tomography; CTCAE: Common Terminology Criteria for Adverse Events; DOR: Duration of objective tumor response; ECOG: Eastern Cooperative Oncology Group; EGFR: Epidermal growth factor receptor; ELISA: Enzymelinked immunosorbent assay; HR: Hazard ratio; IV: Intravenously;

MAb: Monoclonal antibody; NCA: Noncompartmental analysis; NSCLC: Nonsmall cell lung cancer; ORR: Objective response rate; OS: Overall survival; PAMP: Pathogen-associated molecular pattern; PD-1: Programmed death-1; PDL-1: Programmed death ligand-1; PFS: Progression-free survival;

PK: Pharmacokinetic; PR: Partial response; PS: Performance status; Q3W: Each 3-week cycle; RECIST: Response Evaluation Criteria in Solid Tumors; SD: Stable disease; $t_{1 / 2}$ : Elimination half life; $t_{\text {max }}$ : Time of maximum concentration; VEGF: Vascular endothelial growth factor; VEGFR2: Vascular endothelial growth factor receptor 2; Vss: Volume of distribution at steady-state

\section{Acknowledgments}

The authors would like to acknowledge all the patients who participated in this study as well as additional investigators of the BTH1677 NSCLC Study Team including Prof. Martin Wolf, MD, Clinic Kassel GmbH, Medical Clinic IV, Clinic for Haematology and Oncology, Germany; Christian Schumann, MD, Universitätsklinikum Ulm, UIm, Germany; J. Thaddeus Beck, MD, Highlands Oncology Group, Rogers, AR, USA; Wolfgang Schütte, MD, Hospital MarthaMaria, Halle Dölau, Clinic for Internal Medicine II, Halle (Saale), Germany; Jens Kollmeier, MD, Helios Clinic Emil von Behring, Lung Clinic Heckeshorn, Specialist Department 1: Clinic for Pneumology, Pneumological Oncology, Berlin, Germany; Prof. Frank Griesinger, MD, Pius-Hospital Oldenburg, Centre of Radiotherapy and Medical Oncology, Dept. Medical Oncology, Oldenburg, Germany; Nashat Gabrail, MD, Gabrail Cancer Center - Canton, Canton, OH, USA; Athanassios Argiris, MD, University of Texas Health Science Center at San Antonio Cancer Therapy and Research Center, San Antonio, TX, USA; Martin Sebastian, MD, Clinic of Johannes Gutenberg University of Mainz, III. Medical Clinic, Mainz, Germany; Nandagopal Vrindavanam, MD, Signal Point Clinical Research Center, LLC, Middletown, OH, USA; Satish Shah, MD, Gettysburg Cancer Center, Gettysburg, PA, USA; Veena Charu, MD, Pacific Medical Center, Anaheim, CA, USA; Benjamin George, MD, San Antonio Military Medical Center, Ft. Sam Houston, TX, USA; Vincent Hansen, MD, Northern Utah Associates, Ogden, UT, USA; Neil Senzer, MD, Mary Crowley Medical Research Center, Dallas, TX, USA; David Zenk, MD, lowa Blood and Cancer Care, Medical Office Plaza, Cedar Rapids, IA, USA. The authors would also like to acknowledge former Biothera Pharmaceuticals, Inc. employees Ada Braun, MD, PhD and Corina Taitt, MD for assistance in closing the study, data cleaning, and data analysis as well as current Biothera Pharmaceuticals, Inc. employees Mable Ma, PhD for data review and Blaine Rathmann, BS and Katie Ertelt, BS for assistance in assaying beta glucan levels in serum samples. Also acknowledged are Susan Goebel for assistance in statistical programming, VirtualScopics, Inc. for blinded central radiology reviews and analysis, and Chastity Bradley, PhD and Molly Nixon, PhD of Synchrogenix for medical writing assistance.

\section{Funding}

This work was supported by Biothera Pharmaceuticals, Inc. 


\section{Availability of data and materials}

At this time, Biothera does not provide access to individual patient data due to the study protocol's requirements for patient privacy and confidentiality. Only regulatory authorities and Biothera may have access to individual patient data. All data generated (by treatment group) or analyzed during this study are included in this published article.

\section{Authors' contributions}

The individual contributions of each author have been outlined below: Conception and design: FS, JL, MG, MLP. Development of methodology: JRT, RW. Acquisition of data (provided animals, acquired and managed patients, provided facilities, etc.): WE-R. Analysis and interpretation of data (e.g. statistical analysis, biostatistics, computational analysis): JRT, MMT, MD, JL, RDH, MLP. Writing, review, and/or revision of the manuscript: WE- $R, J L, P M, J R T$, $\mathrm{RDH}, \mathrm{MG}, \mathrm{MLP}, \mathrm{RW}, \mathrm{MMT}, \mathrm{MD}, \mathrm{FS}$. Administrative, technical, or material support (i.e., reporting or organizing data, constructing databases): JL, PM, JRT, MMT, MD. Study supervision: JL, PM, MLP. All authors read and approved the final manuscript.

\section{Authors' information}

Not applicable.

\section{Ethics approval and consent to participate}

Prior to enrollment, all study materials were approved by the governing ethics committee, Technical University Munich, Faculty for Medicine, Ethics Committee, Ismaninger Str. 22, 81,675 Munich, Germany (Project No. 2292/ 08; EudraCT No. 2008-006780-37) or institutional review boards (Schulman Associates IRB, Inc., 4445 Lake Forest Drive, Suite 300, Cincinnati, OH 45242 USA; Compass Independent Review Board, LLC, 5416 East Baseline Rd., Suite 120, Mesa, AZ 85206 USA; Mary Crowley Medical Research Center, Institutional Review Board, 1700 Pacific Avenue, Suite 1100, Dallas, TX 75201 USA [no patients were enrolled]; UT Health Science Center San Antonio, Institutional Review Board, Mail Code 7830, 7703 Floyd Curl Drive, San Antonio, TX 78229 USA; Brooke Army Medical Center Institutional Review Board, 3551 Roger Brooke Dr., Fort Sam Houston, TX 78234 USA [no patients were enrolled]) at each site. This study was conducted in full accordance with the Good Clinical Practice: Consolidated Guideline approved by the International Conference on Harmonisation and all other applicable national and local laws/regulations. Adult patients who had given written informed consent were eligible to participate in the study.

\section{Consent for publication}

Not applicable.

\section{Competing interests}

WE-R has received honoraria from Eli Lilly and Company, BoehringerIngelheim, Roche, BMS, and Merck. At the time this study was performed, $J$, $\mathrm{PM}, \mathrm{RDH}, \mathrm{MG}, \mathrm{MLP}$, and RW were employed in leadership roles at Biothera Pharmaceuticals Inc. and owned stock/stock options in Biothera Pharmaceuticals Inc. MMT and MD were compensated by Biothera for pharmacokinetic and data analysis assistance. JRT was compensated by Biothera for statistical analysis assistance. FS has no conflicts of interest to disclose.

\section{Publisher's Note}

Springer Nature remains neutral with regard to jurisdictional claims in published maps and institutional affiliations.

\footnotetext{
Author details

${ }^{1}$ Kliniken der Stadt Köln gGmbH, Krankenhaus Merheim, Thoraxchirurgische u. Pneumologische Klinik, Ostmerheimer Str. 200, 51109 Köln, Germany. ${ }^{2}$ Biothera Pharmaceuticals, Inc., 3388 Mike Collins Drive, Suite A, Eagan, MN 55121, USA. ${ }^{3}$ Rutgers University, 82 Rittenhouse Circle, Newtown, PA 18940, USA. ${ }^{4}$ Certara Strategic Consulting, 2000 Peel Street, Suite 570, Montréal, Québec H3A2WS, Canada. ${ }^{5}$ Medical Clinic and Polyclinic of Klinikum rechts der Isar of Technical University Munich, Ismaninger Str. 22, 81675 Munich, Germany. ${ }^{6}$ PresentAddress: Immuno Research, Inc., 3388 Mike Collins Drive, Suite B, Eagan, MN 55121, USA.
}

Received: 19 October 2017 Accepted: 13 February 2018

Published online: 27 February 2018

\section{References}

1. American Cancer Society: Lung cancer (non-small cell) 2017. http://www. cancer.org/cancer/lungcancer-non-smallcell/detailedguide/non-small-celllung-cancer-key-statistics. Accessed 15 Sept 2016.

2. Ettinger DS, Wood DE, Akerley W, Bazhenova LA, Borghaei H, Camidge DR, et al. NCCN Guidelines Insights: Non-Small Cell Lung Cancer, Version 4.2016. J Natl Compr Canc Netw. 2016;14:255-64.

3. Besse B, Adjei A, Baas P, Meldgaard P, Nicholson M, Paz-Ares L, et al. 2nd ESMO consensus conference on lung cancer: non-small-cell lung cancer first-line/second and further lines of treatment in advanced disease. Ann Oncol. 2014;25:1475-84

4. Masters GA, Temin S, Azzoli CG, Giaccone G, Baker S Jr, Brahmer JR, et al. Systemic therapy for stage IV non-small-cell lung cancer: American Society of Clinical Oncology clinical practice guideline update. J Clin Oncol. 2015;33: 3488-515.

5. Avastin ${ }^{\oplus}$ [package insert]. San Francisco: Genentech, Inc; 2015.

6. Portrazza ${ }^{\mathrm{TM}}$ [package insert]. Indianapolis: Eli Lilly and Company; 2015.

7. Keytruda ${ }^{\circledR}$ [package insert]. Whitehouse Station: Merck \& Co, Inc; 2014

8. Cyramza ${ }^{\oplus}$ [package insert]. Indianapolis: Eli Lilly and Company; 2014.

9. Opdivo ${ }^{\oplus}$ [package insert]. Princteon: Bristol-Myers Squibb Company; 2017.

10. Tecentriq ${ }^{\oplus}$ [package insert]. San Francisco: Genentech, Inc; 2016.

11. Jain RK. Antiangiogenesis strategies revisited: from starving tumors to alleviating hypoxia. Cancer Cell. 2014;26:605-22.

12. Ohm JE, Carbone DP. VEGF as a mediator of tumor-associated immunodeficiency. Immunol Res. 2001;23:263-72.

13. Ferrara N, Hillan KJ, Gerber HP, Novotny W. Discovery and development of bevacizumab, an anti-VEGF antibody for treating cancer. Nat Rev Drug Discov. 2004;3:391-400.

14. Sandler A, Gray R, Perry MC, Brahmer J, Schiller JH, Dowlati A, et al. Paclitaxel-carboplatin alone or with bevacizumab for non-small-cell lung cancer. N Engl J Med. 2006;355:2542-50.

15. Reck M, von Pawel J, Zatloukal P, Ramlau R, Gorbounova V, Hirsh V, et al. Phase III trial of cisplatin plus gemcitabine with either placebo or bevacizumab as first-line therapy for nonsquamous non-small-cell lung cancer: AVAiL. J Clin Oncol. 2009;27:1227-34.

16. Reck M, von Pawel J, Zatloukal P, Ramlau R, Gorbounova V, Hirsh V, et al. Overall survival with cisplatin-gemcitabine and bevacizumab or placebo as first-line therapy for nonsquamous non-small-cell lung cancer: results from a randomised phase III trial (AVAiL). Ann Oncol. 2010;21:1804-9.

17. Chan AS, Jonas A, Qui X, Ottoson NR, Walsh RM, Gorden KB, et al. Imprime PGG-mediated anti-cancer immune activation requires immune complex formation. PLoS One. 2016;11:e0165909.

18. Bose N, Chan AS, Guerrero F, Maristany CM, Qiu X, Walsh RM, et al. Binding of soluble yeast beta-glucan to human neutrophils and monocytes is complement-dependent. Front Immunol. 2013:4:230.

19. Chan ASH, Qiu X, Bykowski Jonas A, Patchen ML, Bose N. Imprime PGG, a yeast beta glucan immunomodulator, has the potential to repolarize human monocyte-derived M2 macrophages to M1 phenotype. J Immunother Cancer. 2014;2(Suppl 3):191.

20. Chan ASH, Qiu X, Jonas A, Kangas T, Ottoson NR, Bose N. Imprime PGG modulates the function of monocyte-derived M2 macrophages and dendritic cells to drive T cell expansion. Cancer Res. 2015;75(Suppl 15):LB225.

21. Leonardo S, Gorsen K, Fulton R, Fraser K, Kangas T, Walsh R, et al. Immune profiling via multiplexed immunofluopresence shows that Imprime based anti-cancer efficacy involves profound changes in macrophase polarization, type 1 IFN signaling and formation of immune clusters [abstract]. Society for Immunotherapy of cancer. National Harbor; 2016. Abstract 468

22. Fraser K, Ottoson N, Qiu X, Chan ASH, Jonas A, Kangas T, et al. Imprime PGG modulates the myeloid component of the tumor microenvironment to coordinate an anti-tumor immune response. Cancer Res. 2016;76(Suppl 3):A02.

23. Fraser K, Chan A, Qiu X, Ottoson N, Bykowski Jonas A, Graff J, et al. Imprime PGG, a novel, clinical-stage pathogen associated molecular pattern, modulates MDSC function, facilitating a coordinated antitumor immune response. Cancer Immunol Res. 2016;4(11 Suppl):A128.

24. Leonardo SM, Gorden K, Fulton R, Wurst L. Imprime PGG decreases regulatory $T$ cell suppression and enhances $T$ cell proliferation and differentiation revealing additional mechanisms for its anti-tumor activity. Cancer Res. 2015;75(Suppl 15):5034. 
25. Bose N, Fulton R, Chan A, Leonardo S, Fraser K, Jonas A, et al. Imprime PGG, a yeast-derived pathogen-associated molecular pattern (PAMP), drives a coordinated anti-cancer immmune attack [abstract]. Symposia on cancer research: emerging concepts in host response to cancer. Houston. 2015.

26. Bose N, Chan ASH, Bykowski Jonas A, Qiu X, Ottoson NR, Kangas T, et al. Imprime PGG treatment elicits a coordinated antitumor immune response that triggers enhanced expression of PD-L1 on tumor cells as well as monocyte-derived macrophages and dendritic cells. Cancer Res. 2015; 75(Suppl 15):LB228.

27. Fulton RB, Leonardo SM, Michel KS, Danielson ME, Gorden K, Graff JR. Imprime PGG, a soluble beta-glucan, binds to and activates dendritic cells resulting in enhanced T cell priming, expansion, and cytokine production. Cancer Immunol Res. 2016;4:B019.

28. Li B, Allendorf DJ, Hansen R, Marroquin J, Ding C, Cramer DE, et al. Yeast beta-glucan amplifies phagocyte killing of iC3b-opsonized tumor cells via complement receptor 3-Syk-phosphatidylinositol 3-kinase pathway. J Immunol. 2006;177:1661-9.

29. Li B, Allendorf DJ, Hansen R, Marroquin J, Cramer DE, Harris CL, et al. Combined yeast \{beta\}-glucan and antitumor monoclonal antibody therapy requires C5a-mediated neutrophil chemotaxis via regulation of decayaccelerating factor CD55. Cancer Res. 2007;67:7421-30.

30. Qi C, Cai Y, Gunn L, Ding C, Li B, Kloecker G, et al. Differential pathways regulating innate and adaptive antitumor immune responses by particulate and soluble yeast-derived beta-glucans. Blood. 2011;117:6825-36.

31. Bose N, Gorden K, Chan A, Bykowski Jonas A, Ottoson N, Walsh R, et al. Innate immune modulation: the novel immunotherapeutic Imprime PGG triggers the anti-cancer immunity cycle in concert with tumortargeting, anti-angiogenic, and checkpoint inhibitor antibodies [abstract]. AACR, tumor immunology and immunotherapy. Boston; 2016. Abstract B29

32. Jonas A, Chan A, Ottoson N. Imprime PGG drives adaptive immune resistance within the tumor microenvironment by modulating the myeloid compartment and enhances the efficacy of anti-PD1 antibody in vivo [abstract]. Annual meeting of the American Association for Cancer Research. New Orleans; 2016. Abstract LB087

33. Fraser K, Chan A, Fulton R, Leonardo S, Jonas A, Qiu X, et al. Imprime PGG triggers PD-L1 expression on tumor and myeloid cells and prevents tumo establishment in combination with anti-PD-L1 treatment in vivo [abstract]. Annual meeting of the American Association for Cancer Research. New Orleans; 2016. Abstract 2335

34. Salvador C, Li B, Hansen R, Cramer DE, Kong M, Yan J, et al. Yeast-derived beta-glucan augments the therapeutic efficacy mediated by anti-vascular endothelial growth factor monoclonal antibody in human carcinoma xenograft models. Clin Cancer Res. 2008;14:1239-47.

35. Zhong W, Hansen R, Li B, Cai Y, Salvador C, Moore GD, et al. Effect of yeastderived beta-glucan in conjunction with bevacizumab for the treatment of human lung adenocarcinoma in subcutaneous and orthotopic xenograft models. J Immunother. 2009;32:703-12.

36. Fraser K, Ottoson N, Qiu X, Chan ASH, Jonas A, Kangas T, et al. Imprime PGG triggers a coordinated anti-cancer immune response in concert with antiangiogenic antibodies, re-polarizing the immune microenvironment to suppress tumor growth. Mol Cancer Ther. 2015;14(12 Suppl 2):A3.

37. Fraser K, Ottoson N, Qiu X, Chan ASH, Jonas A, Kangas T, et al. Imprime PGG synergizes with anti-angiogenic antibodies to repolarize the immune microenviornment, suppressing xenograft tumor growth in vivo [abstract]. Annual meeting of the American Association for Cancer Research. New Orleans; 2016. Abstract 3280

38. Halstenson CE, Shamp T, Gargana MA, Walsh RM, Patchen ML. Two randomized, double-blind, placebo-controlled, dose-escalation phase 1 studies evaluating BTH1677, a 1, 3-1,6 beta glucan pathogen associated molecular pattern, in healthy volunteer subjects. Investig New Drugs. 2016;34:202-15.

39. Cornelio G, Tamayo M, Flores ML, Bautista JB, Tioleco PS, Gargano MA, et al. A phase Ib/ll study evaluating the safety, pharmacokinetics, and efficacy of BTH1677 in combination with cetuximab with and without irinotecan in patients with advanced metastatic colorectal cancer. Colorectal Cancer. 2016:5:95-108

40. Thomas M, Sadjadian P, Kollmeier J, Lowe J, Mattson P, Trout JR, et al. A randomized, open-label, multicenter, phase II study evaluating the efficacy and safety of BTH1677 (1,3-1,6 beta glucan; Imprime PGG) in combination with cetuximab and chemotherapy in patients with advanced non-small cell lung cancer. Investig New Drugs. 2017;35:345-58.
41. Green FL, Page DL, Fleming ID, Fritz AG, Balch CM, Haller DG, et al., editors. American joint committee on cancer cancer staging manual. 6th ed. Philadelphia: Lippincott Raven Publishers; 2002.

42. Forde PM, Reiss KA, Zeidan AM, Brahmer JR. What lies within: novel strategies in immunotherapy for non-small cell lung cancer. Oncologist. 2013;18:1203-13.

43. Shepherd FA, Douillard JY, Blumenschein GR Jr. Immunotherapy for nonsmall cell lung cancer: novel approaches to improve patient outcome. J Thorac Oncol. 2011;6:1763-73.

44. Carbone DP, Gandara DR, Antonia SJ, Zielinski C, Paz-Ares L. Non-small-cell lung cancer: role of the immune system and potential for immunotherapy. J Thorac Oncol. 2015;10:974-84.

45. Brahmer JR. Harnessing the immune system for the treatment of non-smallcell lung cancer. J Clin Oncol. 2013;31:1021-8.

46. Vesely MD, Kershaw MH, Schreiber RD, Smyth MJ. Natural innate and adaptive immunity to cancer. Annu Rev Immunol. 2011;29:235-71.

47. Manegold C, Dingemans AC, Gray JE, Nakagawa K, Nicolson M, Peters S, et al. The potential of combined immunotherapy and antiangiogenesis for the synergistic treatment of advanced NSCLC. J Thorac Oncol. 2017;12:194-207.

\section{Submit your next manuscript to BioMed Central and we will help you at every step:}

- We accept pre-submission inquiries

- Our selector tool helps you to find the most relevant journal

- We provide round the clock customer support

- Convenient online submission

- Thorough peer review

- Inclusion in PubMed and all major indexing services

- Maximum visibility for your research

Submit your manuscript at www.biomedcentral.com/submit
Biomed Central 